José Alejandro Mosqueda Esparza 


\section{La aflicción del hombre moderno ante la «voluntad de poder» de Friedrich Nietzsche}

\section{Planteamiento}

Aflicción no es un término que mencione Nietzsche a propósito del hombre moderno, sin embargo, y ésta es la tesis que se intenta demostrar, esta palabra responde a la manera en la que actúa el moderno en relación a su «voluntad de poder», es decir, ante el carácter propenso a dominar que para Nietzsche se manifiesta en todas las funciones básicas de lo vivo. Es el modo o los caminos por los que el moderno ha buscado dominar, lo que da muestra de su congoja ante su «voluntad de poder».

Nietzsche plantea que la única realidad a la que tenemos acceso es a la de nuestra vida instintiva. Es decir, que la única expresión de la vida de la que nosotros tenemos cierto tipo de experiencia «directa» ${ }^{1}$ es la de nuestro mundo de apetitos y pasiones. Ahora bien, ¿cómo explicar nuestra vida instintiva? Pues mediante una tesis que la designe y defina desde su carácter inteligible, a saber, la «voluntad de poder». Por lo tanto, la «voluntad de poder» no define a la vida entendida como otra realidad externa a nosotros, sino que designa el carácter de la única expresión de la vida a la que tenemos acceso directo, esto es, de nuestro mundo de apetitos y pasiones. En este sentido el hombre es un conglomerado de voluntades de poder y el cuerpo es un conjunto de centros vitales que luchan entre sí.

La idea de hombre moderno que se encuentra en Nietzsche es la de un organismo que no quiere hacer de más, que no busca crear algo grande, ni superar obstáculos, que no actúa por mor de un mayor poder. Esto hace pensar que no es que el moderno haya eliminado su «voluntad de poder», sino que le molesta, le inquieta, le angustia actuar a partir de eso que define el carácter de sus funciones más básicas, a saber, de su «voluntad de poder». El tratar de reprimir su instinto cardinal revela, pues, la aflicción del hombre moderno.

Por lo tanto, en este ensayo se busca responder a dos preguntas: ¿cómo llega a ser la aflicción una manera de actuar del hombre?,

1 Ver D. Sánchez Meca, El nibilismo. Perspectivas sobre la bistoria espiritual de Europa, España, Editorial Síntesis, 2004, p. 128. 
y, ¿cómo se demuestra dicha aflicción en el hombre moderno del que habla Nietzsche?

\section{I. «Voluntad de poder»}

Imaginemos una función de marionetas en un imponente teatro. Nosotros como espectadores, vemos a una marioneta representar un personaje; observamos que la marioneta mueve sus extremidades, su cabeza, su cintura, su boca. Sale de escena dicha marioneta y entra otra. En ésta observamos lo mismo, un movimiento corporal e incluso cierto ímpetu por actuar. Sale también, y entran otras cuatro o cinco... termina la función. Lo común en todas las marionetas es el movimiento corporal y el impulso a actuar; siendo en unas mayor y en otras menor. Ahora supongamos que salimos del teatro un poco intrigados por el movimiento e impulso de las marionetas. Cabría preguntarnos en ese momento: ¿qué hay detrás de una marioneta?, ¿qué la impulsa a moverse?, ¿cuál es el nombre de aquella mano que sostiene la cruceta?... o dejando de imaginar: ¿qué hay detrás del teatro de los hombres?

En Nietzsche encontramos un escenario similar cuando en Así habló Zaratustra ${ }^{2}$ se pregunta: «¿Qué es lo que persuade a lo viviente a obedecer y a mandar y a ejercer obediencia incluso cuando manda?», 3 a lo cual se responde:

En todos los lugares donde encontré seres vivos encontramos voluntad de poder; e incluso en la voluntad del que sirve encontré voluntad de ser señor. A servir al más fuerte, a eso persuádele al más débil su voluntad, la cual quiere ser dueña de lo que es más débil todavía, a ese solo placer no le gusta renunciar. ${ }^{4}$

Definir el carácter de la vida como «voluntad de poder», implica también reconocer la condición de todo lo vivo por dominar. Los impulsos son los que imponen, y en este sentido no hay lugar para la

2 Después de percibir y observar que todo viviente obedece al que le impone su fuerza.

3 F. Nietzsche, Así habló Zaratustra (trad. Andrés Sánchez Pascual), España, Alianza Editorial, 1997, p. 176.

4 Idem. 
compasión, ya que también los más débiles se persuaden de enseñorear, sólo que lo hacen en un menor grado y con una menor fuerza.

La fuerza que domina impone un sentido a sus interpretaciones, anulando por consiguiente, el sentido de interpretaciones pasadas. El dominio se da en diversos grados, por ejemplo, en el individuo y su conglomerado de fuerzas, en la sociedad y el domino de las fuerzas mayores, etcétera. En la medida en que una fuerza mayor domina sobre fuerzas menores, impone su interpretación del mundo. Una fuerza mayor crea, según sus impulsos dominantes, un lenguaje, entonces ese lenguaje interpreta el mundo según sus impulsos más fuertes. Si una sociedad en cierto momento es sometida por cierta fuerza, y en dicha fuerza impera cierto impulso de interpretación, entonces las fuerzas menores que son sometidas por esa fuerza mayor son también dominadas por el impulso de interpretación de la fuerza mayor que subyuga en ese momento a dicha sociedad. Por lo tanto, todo enseñorearse es reinterpretar a partir de cierto impulso dominante.

Son dos puntos importantes en la tesis de la «voluntad de poder» tanto el enseñorear como el reinterpretar. Pero, entonces, ¿qué podemos entender por «voluntad de poder»? Con el término de «voluntad de poder» Nietzsche designa el carácter de dominio en lo vivo, enfatizando así su condición por ejercer mando. Con ello, Nietzsche alude a la lucha instintiva que se da en nuestro mundo de apetitos y pasiones, explicando a partir de este mundo cualquier acontecimiento.

\section{Lo «sano»y lo «enfermo»}

Como se dijo en el apartado anterior, todo ser vivo posee el carácter de «voluntad de poder». Lo vivo tiende a hacer cosas de más, a buscar vencer grandes dificultades, a ejercer dominio. Pero en el hombre ocurre algo que lo convierte en un animal enfermizo, ya que él no es un ser tan determinado como en el caso de los demás animales.

Hay muchas variantes del tipo animal hombre. Variantes tales como guerrero, asceta, filósofo, sacerdote, etcétera. Nietzsche describe por ejemplo, a un tipo de hombre «aristócrata» como un hombre activo, noble, poderoso, que se mira a sí mismo, un hombre creador. De igual forma describe un tipo "esclavo», en el que se muestra imposibilidad fisiológica, debilidad, pasividad, un tipo reactivo que no actúa por sí mismo. Esta concepción de las variantes o tipos de hombres no pretende clasificar al hombre, sino mostrar lo diverso y complejo que 
es; ya que pueden existir diversos tipos de ser humano que incluso sean opuestos. Este carácter múltiple del hombre es lo que lo convierte en un animal más complejo, más delicado, un animal que puede descomponerse más fácilmente: un animal enfermizo. Lo cual significa que su diversidad lo hace más propenso a decaer.

Pero también existen dos amplios estados del hombre, que son lo «sano» y lo «enfermo». Estos estados determinan la situación instintiva del hombre y, por ende, su posibilidad para desarrollarse en su tipo. Cada ser vivo tiene ciertas posibilidades para alcanzar una potencialidad y una magnificencia sumas..$^{5}$ Los tipos de hombre determinados por su estado emprenden un camino hacia su magnitud o su decadencia. ¿Cómo ha actuado el hombre en este camino?

Para hablar de la manera en la que el hombre ha actuado es necesario atender dos conceptos que propone Nietzsche. El primero de ellos es la «certeza instintiva ${ }^{6}$ y el segundo la "anarquía de los instintos». ${ }^{7} \mathrm{El}$ primero nos señala una organización en la que los instintos pueden dirigirse hacia una meta; el segundo nos indica una falta de gobierno en los instintos por lo que unos a otros se estorban impidiendo alguna dirección hacia algún fin. La función de estas dos denominaciones se entiende en relación con el término de décadence. En general Nietzsche designa con este término a lo que separa al hombre de la obtención de un mayor poder. Si el hombre es un animal enfermizo y al ser enfermizo es frágil, entonces el animal hombre es décadence en cuanto que su condición lo separa de la posibilidad de obtener un mayor poder o de ejercer un mayor dominio.

Sin embargo, la «certeza instintiva» hace que partiendo de nuestra condición de décadence podamos aspirar hacia una meta, que podamos superarnos e ir más allá de nuestra condición. Lo anterior gracias al dominio que se ejerce sobre determinado caos instintivo. Esta primera manera de actuar está caracterizada por la elección instintiva de lo que nos hace bien $y$, al mismo tiempo, instintivamente

5 Cfr. F. Nietzsche, La genealogía de la moral, (trad. Andrés Sánchez Pascual), España, Alianza Editorial, 2000, prólogo-6, p. 28.

6 Este término aparece en F. Nietzsche, Ecce Homo, cómo se llega a ser lo que se es (trad. Andrés Sánchez Pascual), España, Alianza Editorial, 2001, p. 28.

7 Término que se puede derivar del $\$ 258$, en F. Nietzsche, Más allá del bien y del mal (trad. Andrés Sánchez Pascual), México, Alianza Editorial, 1997, p. 220; y en F. Nietzsche, Nietzsche contra Wagner (trad. José Luís Arántegui), España, Siruela, 2002, p. 35. 
descarta lo que nos daña. La «certeza instintiva» es propia, pues, de un hombre «sano».

Por otro lado, la «anarquía de los instintos» manifiesta una disgregación de los impulsos conglomerados en el hombre en donde ningún impulso domina sobre otro, sino que se estorban unos con otros y, por lo tanto, no logran dirigirse hacia una meta. Sin el gobierno de sus instintos el hombre elige lo que le daña. Esta manera de actuar es propia de un hombre «típicamente enfermo».

Así, dentro de la manera general de la décadence existen hombres «sanos»y hombres «típicamente enfermos». Los primero confían en sus elecciones instintivas y organizan sus impulsos. Por otro lado, los hombres «típicamente enfermos» descienden en su condición de décadence. La «anarquía de los instintos» continúa con el caos de sus fuerzas en el que se incapacita al individuo para dirigirse hacia una sola meta, orillándolo a elegir lo que daña y frenando la posibilidad de superarse a sí mismo.

No hay un único tipo de salud puesto que, como se dijo, no hay tampoco un solo tipo de hombre. Cada hombre necesita, de cierta armonía de sus instintos en la que dominen los impulsos necesarios para el tipo de hombre que se es. Por ejemplo, si existe un hombre del tipo músico ese hombre escogería instintivamente lo que lo encaminaría hacia su plenitud como músico, y de la misma manera se alejaría de todo lo que lo dañara o lo separara de su plenitud como músico. Sería irónico pedirle a un músico que escogiera aquello que necesita un actor para llegar a su plenitud. $\mathrm{O}$ lo que es lo mismo, pedir a un músico que eligiera instintivamente aquello que lleva a la plenitud a un no-músico, por lo tanto, que lo distanciara de la plenitud de su tipo. Más que irónico sería un síntoma de décadence el que nuestros instintos elijan aquello que nos aparta de la obtención de nuestra plenitud. «Sentir dañino lo dañino, poder prohibírselo uno mismo, es aún signo de juventud, de fuerza». ${ }^{8}$

Al hombre «sano» le es posible sanarse a sí mismo de su condición enfermiza, es un décadent en cierto sentido, pero un décadent que busca superarse a sí mismo, que se cura a partir de sí mismo y de sus necesidades.

Un hombre «típicamente enfermo» con respecto al «sano» es un hombre que ya no confía en sus instintos, en el que no existe un gobierno ni un orden en sus fuerzas y, por lo tanto, en el que el

8 F. Nietzsche, Nietzsche contra Wagner, p. 31. 
carácter de «voluntad de poder» se disgrega, ya que sus instintos no constituyen una armonía que logre dirigirse en función de una única meta. «Elegir instintivamente lo dañoso para uno mismo, ser-atraído por motivos "desinteresados" es algo que casi nos da la fórmula de la décadence». ${ }^{9} \mathrm{Y}$ todo «error, en todo sentido, es consecuencia de una degeneración de los instintos, de una disgregación de la voluntad $\gg .^{10}$ El hombre «típicamente enfermo» termina combatiendo sus propios instintos, en él terminan preponderando los sentimientos de displacer sobre los de placer: ${ }^{11}$

Es posible distinguir tres niveles [...] del uso que hace Nietzsche de los términos salud y enfermedad (décadence). En el primero de ellos se haría referencia a las enfermedades particulares, como la gripa o la sífilis; en el segundo se hablaría de una enfermedad relativa, o décadence concreta, podría decirse, la de una persona, o la de un pueblo, por ejemplo, o la de un tipo humano; y en el tercer nivel se hablaría de la décadence como tal, o de la enfermedad como tipo: el «ser típicamente enfermo», el tipo de la décadence y expresiones similares. ${ }^{12}$

Podemos decir en un primer nivel, que un hombre se encuentra enfermo señalando un estado particular de un individuo -por ejemplo, al señalar el estado enfermizo del hombre. En un segundo nivel, que un hombre se encuentra enfermo o sano con respecto a otro tipo de hombre. Y, por último, que un hombre es «típicamente enfermo» o «típicamente sano» en un tercer nivel, a saber, cuando elige instintivamente lo que le es dañino y nunca logra curarse a sí mismo o cuando elige instintivamente siempre lo que le hace bien y puede curarse a sí mismo.

De esta forma, nos es posible argumentar a continuación, 1) que el hombre moderno es un animal enfermo con respecto a lo que era el hombre «aristocrático», esto en un segundo nivel, 2) con res-

9 F. Nietzsche, Crepúsculo de los ídolos o Cómo se filosofa con el martillo (trad. Andrés Sánchez Pascual), España, Alianza Editorial, 1997, p. 108.

10 Ibidem, p. 63.

11 Cfr. F. Nietzsche, El Anticristo (trad. Andrés Sánchez Pascual), España, Alianza Editorial, 1998, p. 45.

12 J. A. Chávez, Nietzsche. De la verdad deshonesta al pensamiento noble, México, Universidad Autónoma de Aguascalientes, 2008, p. 52. 
pecto a la fuerza griega también en un segundo nivel y, 3) en conclusión, un animal «típicamente enfermo» en un tercer nivel: un hombre moderno que no puede curarse a sí mismo. De esta manera damos por sentadas las bases del pensamiento de Nietzsche que sirven como fundamento de los siguientes apartados.

\section{El moderno respecto al tipo «aristócrata»}

Este primer contraste del hombre moderno con el hombre «aristócrata» es hecho a partir del origen de los juicios «bueno» «malo», «bueno» «malvado», y del concepto «mala conciencia».

Comencemos trazando el origen de los juicios de valor «bueno» y «malo». El concepto y juicio de «bueno» se origina a partir de los «buenos» mismos, es decir, de los nobles. Aquellos que se sintieron y se valoraron a sí mismos, a lo que ellos mismos hacían como «bueno». Nace, pues, a partir de que el noble se mira a sí mismo «como algo de primer rango, en contraposición a todo lo bajo, lo abyecto, vulgar y plebeyo. Partiendo de ese pathos de la distancia es como se arrogaron el derecho de crear valores ${ }^{13}$ Es ese mismo pathos de los nobles el que crea el concepto y juicio de «malo», denominando con ello a un hombre simple, vulgar, plebeyo. En este sentido lo «malo» sólo es aquello distante a lo «bueno».

El hombre noble interpreta y crea valores a partir de sí mismo. Posee cierto orden en sus instintos, en su lucha de fuerzas, llámense impulsos, que le permiten dirigirse hacia una meta. No le importa desbordar sus fuerzas por mor de un mayor poder. Por lo tanto, en su manera de actuar y de valorar vemos síntomas de un animal saludable.

Pero también existe la forma de valorar de los hombres del tipo «esclavo». En éstos, los valores son creados por un sentimiento de recelo, es decir, por un resentimiento. Su manera de valorar tiene como presupuesto la impotencia. Al no poder exteriorizar sus instintos va creciendo dentro de ellos un odio y un deseo de venganza espiritual:

La rebelión de los esclavos en la moral comienza cuando el resentimiento mismo se vuelve creador y engendra valores: el resentimiento de aquellos seres a quienes les está vedada la auténtica reacción, la reacción de la acción, y que se desquitan únicamente

13 F. Nietzsche, La genealogía de la moral, p. 37. 
con una venganza imaginaria [... ] la moral de los esclavos dice no, ya de antemano, a un «fuera», a un «otro», a un «no-yo»; y ese no es lo que constituye su acción creadora. Esta inversión en la mirada que establecen los valores - este necesario dirigirse hacia fuera en lugar de volverse hacia sí- forma parte precisamente del resentimiento: para surgir, la moral de los esclavos necesita siempre primero de un mundo opuesto y externo; necesita, hablando fisiológicamente, de estímulos exteriores para poder actuar, - su acción es, en raíz, una reacción. ${ }^{14}$

Los hombres «esclavos» "crean" en primera instancia lo «malvado» identificándolo con todo lo que no es esclavo, y a partir de esto o en segunda instancia, "crean" lo «bueno». Lo «bueno» viene a ser una repercusión de lo «malvado», ya que el esclavo podría argumentar que como lo que no soy yo es «malvado», la contraparte, o sea yo, tiene que ser «buena».

El hombre es sano cuando elige instintivamente lo que lo fortalece, lo que lo desarrolla, y enfermo cuando busca instintivamente lo que impide su desarrollo, de aquí, que los juicios de valor aristocráticos tengan «como presupuesto una constitución física poderosa, una salud floreciente, rica, incluso desbordante, junto con la que condiciona el mantenimiento de la misma, es decir, [... ] todo lo que la actividad fuerte [...] lleva consigo» ${ }^{15} \mathrm{e}$ incluso un desahogo desmedido de sus instintos naturales. Por otro lado, el «esclavo» por su impotencia, actúa debilitando y reprimiendo el desbordamiento de los instintos: ¿no es acaso que el esclavo no actúa por el hombre, por la superación de sí mismo, sino por la supervivencia del esclavo?, ¿no es acaso reprimir la crueldad o cualquier instinto un evento no-sano que impide su desarrollo?

Por lo que respecta al origen del concepto de la «mala conciencia» Nietzsche es muy claro:

estaban reducidos, estos infelices, a pensar, a razonar, a calcular, a combinar causas y efectos, a su «conciencia», a su órgano más miserable y más expuesto a equivocarse [...] Todos los instintos que no se desahogan hacia fuera se vuelven hacia dentro - esto es lo que yo llamo interiorización del hombre [...] Aquellos terri-

14 Ibidem, p. 50.

15 Ibidem, p. 45. 
bles bastiones con que la organización estatal se protegía contra los viejos instintos de la libertad [...] hicieron que todos aquellos instintos del hombre salvaje, vagabundo, diesen vuelta atrás, se volviesen contra el hombre mismo. La enemistad, la crueldad, el placer en la persecución, en la agresión, en el cambio, en la destrucción -todo esto vuelto contra el poseedor de tales instintos: ése es el origen de la «mala conciencia». ${ }^{16}$

Cuando comienza a prohibirse o a verse como «malvado» la exteriorización de los instintos, es cuando el hombre tiene que utilizar su órgano menos desarrollado y por lo tanto el más propenso a equivocarse. ${ }^{17} \mathrm{Y}$ a partir de esto se comenzó a pensar que el hombre debería ser de éste y de aquel modo:

A los seres humanos se les imaginó «libres» para que pudieran ser juzgados, castigados, para que pudieran ser culpables: por consiguiente, se tuvo que pensar que toda acción era querida, y que el origen de toda acción estaba situado en la conciencia. ${ }^{18}$

De tal forma que se ha hecho al hombre menos dañino, pero también más enfermo.

Así, la «mala conciencia» domestica al hombre, impide que la armonía de los instintos de determinado tipo de hombre pueda desarrollarse. $\mathrm{Si}$ esto es lo que la «mala conciencia» provoca hay algo enfermo en ello, ya que confunde al hombre y evita que pueda dirigirse hacia una meta.

Con todo lo anterior podemos dar respuesta a la siguiente pregunta: ¿por qué el hombre moderno es un animal enfermo en un segundo nivel con respecto al hombre noble? A pesar de que el parecido entre el moderno y el tipo «esclavo» nos dan una pista, la respuesta la ocupa la moral de la décadence del hombre moderno, es decir, su instinto de interpretación dominante que le impide tanto

16 Ibidem, p. 109.

17 Debemos recordar aquí el papel genealógico de Nietzsche, quien no se compromete con una explicación histórica sino que busca en cada término sin procedencia. De este modo, no debemos atender a la «mala conciencia» como un hecho histórico sino como un término que Nietzsche indaga a partir de un estado del hombre.

18 F. Nietzsche, Crepúsculo de los ídolos..., p. 69. 
superarse como curarse a sí mismo. La décadence prominente que padece el hombre moderno es sólo la intensificación de un síntoma, de una enfermedad que se veía en la moral de tradición esclava. La tradición moral ha impedido que el hombre moderno pueda confiar en sus instintos. «Hoy no vemos nada que aspire a ser más grande, barruntamos que descendemos cada vez más abajo, hacia algo más débil, más manso, más prudente, más plácido, más mediocre, más indiferente [... ] se vuelve cada vez "mejor"...». ${ }^{19}$ Pero no parece que este «mejoramiento» moderno, apático, débil, sea el mismo que aquél «mejoramiento» natural que apunta la tesis de la «voluntad de poder». Quizá se deba a que este «mejoramiento» moderno se da a partir de una moral que va en contra del desarrollo del hombre en general.

No podemos negar que la pasividad del «esclavo» tiene alguna similitud con la actual. Que el hombre haya sido domesticado, que sus instintos hayan sido vueltos contra sí mismo y el origen de la «mala conciencia» evocan en la desconfianza y sutilidad de nuestros instintos. Ahora no desbordamos nuestro instinto de crueldad exteriormente, ahora lo desviamos a formas más sutiles, más adecuadas a nuestra décadence. "La suavización de nuestras costumbres [...] es una consecuencia de la decadencia; la índole dura y terrible de la costumbre puede ser, a la inversa, una consecuencia del exceso de vida: entonces, en efecto, es lícito osar mucho, exigir mucho, y también derrochar mucho». ${ }^{20}$

Por lo cual, sólo resta decir que el hombre moderno tiene una tradición moral equiparable a la valoración de los «esclavos», en la que la interpretación surge a partir de otro, de un sentimiento reactivo, en donde no se valora a sí mismo y, por lo tanto, no le importa impedir la organización y, con ello, recuperar la confianza en los instintos. Cuando el hombre moderno antepone su supervivencia a su plenitud, los resultados son una «anarquía de sus instintos» o una desconfianza en ellos y un estancamiento de sus posibilidades. Una decadencia, un grado de décadence en el que el hombre de ser animal enfermizo pasa a ser un animal «típicamente enfermo».

19 F. Nietzsche, La genealogía de la moral, p. 58.

20 F. Nietzsche, Crepúsculo de los idolos..., p. 112. 


\section{El moderno respecto al tipo griego}

La aflicción del hombre moderno concluye con su nibilismo, con su manera de afrontar la vida. ¿Cómo afrontaba el miedo y lo terrible de la existencia el griego? La respuesta reside en la manera en que entendían la fuerza.

Para mostrar la aflicción del hombre moderno ante la fuerza griega, es decir, la diferencia en el modo de ejercer dominio entre el girego y el moderno; recurrimos a un poema sobre la Ilíada y a Wagner. Postulamos el caso de Wagner como un síntoma propio de la decádence.

La palabra que Wagner usa para afrontar lo terrible de la vida, la posibilidad de la muerte, es «redención». Wagner se adscribe a la idea cristiana del «deber creer, por fuerza a hacerlo», ${ }^{21}$ sólo que él lo pronuncia como todo un genio descortés, «dice una cosa y la repite hasta que uno se desespera: hasta que cree». ${ }^{22}$ Pero Wagner no fue desde el principio el artista de la décadence. Su creación de Sigfrido deja ver en él algo de salud:

«¿De dónde vienen todos los males del mundo?», se preguntaba Wagner. De «antiguas capitulaciones», se contestó [...] Dicho en castellano: de usanzas, leyes, morales e instituciones, de todos los pactos en que se basa el antiguo mundo, la vieja sociedad. ¿Y cómo liquidar los males del mundo, la antigua sociedad?» Tan sólo declarando la guerra a tales «capitulaciones» (a lo heredado, a la moral). Eso hace Sigfrido [...] En cuanto algo le cae mal lo despacha de un tajo. ${ }^{23}$

En lo anterior Wagner ha representado la «certeza instintiva» en su personaje de Sigfrido. ¿Qué hecho tuvo que ocurrir para que Wagner pasara a ser el artista de la décadence? Pues Wagner dio con la «filosofía de Schopenhauer; Wagner tocó fondo en una forma contraria de ver el mundo» ${ }^{24}$. Fue tal la manera de decaer de Wagner, que terminó convirtiendo su «certeza instintiva» en «anarquía de los instintos», ahora incluso la zozobra es una meta, incluso afligir o

21 F. Nietzsche, Nietzsche contra Wagner, p. 27.

22 Ibidem, p. 24.

23 Ibidem, p. 29.

24 Idem. 
acongojar el ánimo de los instintos o las fuerzas se convierte en meta. La diferencia ahora es que Wagner se siente necesario como décadent y trata de difundir e imponer el gusto corrompido de sus instintos. Wagner encontró su «redención», su manera de escapar de lo terrible de la vida, en Schopenhauer. «Wagner estaba salvado [... ] Hasta que el filósofo de la décadence no se lo dio, el artista de la décadence no se tuvo». ${ }^{25}$

$\mathrm{Al}$ convertirse en el artista de la décadence el arte de Wagner se convierte en un arte enfermo, toda una galería de enfermos. Nada es tan moderno como la décadence, lo que convierte a Wagner en el artista moderno por excelencia. ${ }^{26}$ Wagner quiso «redimir» la música y a los que escuchaban su música. La «mejor» manera para lograr esto, fue quitarle toda pasión a su música, no permitiendo que la música diera gusto. «iNo demos gusto nunca!», nos dice. Es un décadent que se siente necesario y superior. Pero, ¿cómo no sentirse necesario un artista de la décadence que vive en una atmósfera moderna?

Nietzsche nos da una idea corta y clara sobre lo que es el nibilismo: «al perder el miedo al hombre hemos perdido también el amor a él, el respeto a él, la esperanza en él, más aún, la voluntad de él. Actualmente la visión del hombre cansa - ¿qué es hoy el nihilismo sino es eso?... Estamos cansados de el hombre..+» ${ }^{27}$ Poco es lo que ahora procuramos, a saber, nuestra conservación, que es tan sólo «una de las consecuencias indirectas y más frecuentes de ${ }^{28}$ la vida como «voluntad de poder».

La misma visión cansada, nihilista, es propia de Wagner:

Lo expresivo a cualquier precio como exige el ideal wagneriano, el ideal de la décadence, casa mal con talento. Lo suyo es la virtud, nada más; quiero decir, amaestramiento, automatismo, «negación de sí mismo». Ni gusto, ni voz, ni talento, la escena de Wagner sólo necesita una cosa: igermanos![...] Definición de germano: obediente y piernas largas. ${ }^{29}$

25 Ibidem, p. 30.

26 Cfr. ibid., p. 31.

27 F. Nietzsche, La genealogía de la moral, p. 58.

28 F. Nietzsche, Más allá del bien y del mal, aforismo 13, p. 36.

29 F. Nietzsche, Nietzsche contra Wagner, p. 44. 
Desconsolador el panorama de Wagner, un panorama pesimista, moderno o «típicamente enfermo». Inclusive un panorama moral de interpretación «esclava», en el que es necesario «negarse a sí mismo» por moral. ¿Lucía igual el panorama para un griego?

La respuesta es negativa, la fuerza plasmada en la Ilíada crea un panorama diferente, un panorama vital y natural. La fuerza griega se asimila a la manera de actuar del tipo «aristócrata». Los griegos ${ }^{30}$ entendían que la vida era una lucha de fuerzas y que la guerra era el juego de esa lucha. Admitían a seres desdichados que no tenían ninguna posibilidad en ese juego y seres más fuertes que sometían a aquéllos. Pero también el hombre fuerte entiende que va a llegar un momento en el que una fuerza mayor lo haga perecer. El griego nunca sospechaba de las consecuencias de sus actos, así era su naturaleza de actuar, así lo elegían sus instintos dominantes. «En la Ilíada, la marcha de la guerra consiste solamente en un juego de balanza»». ${ }^{31}$ Semejante al que Nietzsche define como «voluntad de poder», es decir, una la lucha de fuerzas donde domina la mayor. No hay nada de «típicamente enfermo» en el hombre griego. El uso moderado de la fuerza «exigía una virtud más que humana, tan poco habitual como una constante dignidad de la debilidad» ${ }^{32}$

¿Cuál era la forma de afrontar lo terrible de la vida en el griego? Desde el momento en que el griego practica la guerra se da cuenta de la posibilidad de morir. El griego percibe que sus fuerzas llevan consigo el riesgo de la muerte. «El terror, el dolor, el agotamiento, las muertes, los compañeros destruidos, no se puede creer que esas cosas puedan dejar de morder el alma si la embriaguez de la fuerza no viene a ahogarlas». ${ }^{33} \mathrm{La}$ embriaguez es la respuesta de un griego, lo que corresponde también a la visión dionisíaca del mundo.

«El hombre, de hecho, alcanza el gozo de la existencia en dos estados, en el sueño y en la embriaguez».34 Es la genialidad del griego convertir en causa de gozo algo como lo miserable de la vida, tomada ésta con todas sus cualidades: como la crueldad o la muerte, sin que-

30 F. Nietzsche se refiere a los griegos antes de Sócrates.

31 Simone Weil, La fuente Griega (trad. José Luis Escartín), Madrid, Trotta, 2005, p. 25.

32 Ibidem, p. 29.

33 Ibidem, p. 32.

34 F. Nietzsche, El pensamiento trágico de los griegos, escritos póstumos 18701871 (trad. Vicente Serrano), España, Biblioteca Nueva, 2004, p. 120. 
rer eliminar alguna. Es la visión trágica de los griegos la que les permitía reencontrarse con la naturaleza. En ella el hombre no se alejaba de la naturaleza (como en el pesimismo moderno):

Fue necesaria la facilidad y ligereza de la fantasía homérica para apaciguar y temporalmente superar el ánimo desmesuradamente pasional y el sobreagudo entendimiento de los griegos. Si en ellos habla el entendimiento, ¡qué áspera y cruel aparece entonces la vida! No se engañan, pero traman deliberadamente mentiras en torno a la vida. Simónides aconsejaba a sus compatriotas tomar la vida como un juego; demasiado conocida les era la seriedad como dolor (la miseria de los hombres es justamente el tema sobre el cual tanto les gusta a los dioses oír cantar) y sabían que únicamente a través del arte mismo podía la miseria convertirse en goce. ${ }^{35}$

Mediante la tragedia se acepta la miseria del hombre, no la evade sino que la convierte en goce.

A un pesimista moderno le es fácil admitir que la vida estállena de dolor y que lo «mejor» sería no sentir dolor. Con esto está deseando la no-vida. Para evadir la naturaleza de la vida le da imagen a todas las cosas terribles de ella, y de esta manera concibe que no pueden proceder de la propia vida. La tragedia del moderno es justamente eso, tratar de eliminar la tragedia de la vida. El moderno no quiere lidiar con las cualidades terribles de la existencia, es demasiado débil, se encuentra demasiado enfermo para afrontarlo. «Detrás de este modo de pensar y valorar, el cual, mientras sea de alguna manera auténtico, tiene que ser hostil al arte, percibía yo también desde siempre lo hostil a la vida, la rencorosa, vengativa aversión contra la vida misma». ${ }^{36}$

El mito trágico en los griegos cumple con una función diferente consecuente con una época más fuerte, más sana y más valiente. En ellos la tragedia buscaba acercarse a la naturaleza, anhelaba la naturaleza y se aceptaban todas sus contradicciones. Veía lo terrible de la vida sólo como una voluntad en un grado más alto y más amplio. Los

35 F. Nietzsche, Humano, demasiado bumano, vol. I, (trad. Alfredo Brotons Muñoz), Madrid, Akkal, 2001, aforismo 154, p. 122.

36 F. Nietzsche, El nacimiento de la tragedia. "Ensayo de autocrítica", (trad. Andrés Sánchez Pascual), España, Alianza Editorial, 2001, p. 33. 
griegos aceptaban la lucha en su conglomerado de instintos, de igual manera aceptaban la guerra como lucha de fuerzas en una sociedad, y de igual forma aceptaban la vida como una lucha de fuerzas. Todo ello era un signo de salud, de respeto por la vida como «voluntad de poder». La historia natural de la «voluntad de poder» fue entendida en el hombre griego.

\section{Conclusiónł un anhelo de salud}

Como observamos no cabe otra denominación para el hombre moderno con respecto al «aristócrata» o al griego que la de décadent. Pero no sólo un décadent por separarse de su magnitud, sino que termina siendo un hombre «típicamente enfermo» al prevalecer en su elección los sentimientos de displacer sobre los de placer. De tal modo que la decadencia termina mostrándose en un alto grado en el moderno. La aflicción que el hombre moderno muestra sobre su naturaleza, es sólo índice de que pervirtió el modo de ejercer dominio en su moral. La moral se transforma en una forma de ejercer dominio y con ello obstruye el desarrollo de los instintos. Este obstáculo se convierte pues en su moral, y por ello en una manera no-sana de crear valores. La moral del «esclavo» con la que se asemeja el hombre moderno lo priva del desahogo de sus instintos, del dominio de los mismos y lo acarrea hacia una «anarquía de los instintos».

El tipo «aristócrata» o el griego no sufrían ante el carácter básico de lo vivo («voluntad de poder»), la aflicción no era una manera de actuar para ellos. Ello no se debe a que fueran de determinado tipo de hombre, ni se tiene que ser de ese tipo de hombre para no afligirse, sino porque eran hombres «sanos». Eran hombres que desarrollaban sus posibilidades, que confiaban en sus instintos, que contaban con «certeza instintiva», y por lo tanto, que engrandecían a su tipo.

Acaso el hombre moderno se aflige ante su voluntad de poder porque ha sido obstaculizado por su moral, porque ha sido desviado de su magnitud y ahora encontramos en él el síntoma más evidente de la décadence. El hecho de que no podamos quitarnos la etiqueta de modernos quizá se deba a que el hombre moderno no está dispuesto a crear nuevos valores que le permitan consolidarse con su naturaleza, que le permitan superar al moderno. Su mayor obstáculo es superar su situación, su estado «típicamente enfermo». Quizá sea esto último, lo primero que se ha de esperar del moderno. 